\title{
Uterus Weight of Ovariectomized Rats Given Cocoa Powder and Extract
}

\author{
Ariza Budi Tunjung Sari ${ }^{1}$, Misnawi ${ }^{1}$, Pratiwi Pudjiastuti²), and Afaf Baktir ${ }^{2)}$ \\ ${ }^{1)}$ Indonesian Coffee and Cocoa Research Institute, Jl. PB Sudirman 90, Jember 68118, Indonesia \\ ${ }^{2}$ Chemistry Department, Faculty of Science and Technology, Airlangga University, Kampus C Mulyorejo, Surabaya 60115, Indonesia \\ ${ }^{*}$ Corresponding author: ariza.bts@iccri.net
}

\begin{abstract}
Estrogen is a hormone that influences the growth of uterus. Ovariectomized rats lose their ovaries as the main source of estrogen so their uterus tends to shrink. The objective of thise study was to evaluate the potency of cocoa as an estrogen substitute, which was done through an experiment that tested the influence of cocoa products on the uterus weight of ovariectomized rats. There were five treatments and in each of the treatments, six wistar rats were given the substance for three days. Four groups of treatment consisted of ovariectomized rats given cocoa extract ( $875.2 \mathrm{ppm}$ of polyphenols, $1 \mathrm{~g} / \mathrm{kg}$ of body weight, BW), cocoa powder (369.8 ppm of polyphenols, $1 \mathrm{~g} / \mathrm{kg} \mathrm{BW})$, olive oil $(10 \mathrm{~mL} / \mathrm{kg} \mathrm{BW})$, or estradiol valerate $(1 \mathrm{mg} / \mathrm{kg} \mathrm{BW})$. The fifth group consisted of intact (non-ovariectomized) rats given $10 \mathrm{~mL} / \mathrm{kg}$ BW of water. The finding showed that the ovariectomized rats given olive oil had lower uterus weight than that of intact rats, while the ovariectomized rats given estradiol valerate had higher uterus weight compared to the intact and olive oil groups. The ovariectomized rats given cocoa powder and extract had higher uterus weight compared to those given only olive oil; although they were not significantly different. Correlation between the body weight and uterus weight varied across treatment groups. The rats given olive oil showed significant, positive correlation, while the intact rats showed moderate, positive correlation. The rats given estradiol valerate and cocoa powder showed non-significant correlation. Since the polyphenol content in cocoa powder was at lower concentration than that in the cocoa extract, it was predicted that cocoa polyphenols are more potential in the lower concentration. This study concludes that even though consumption of cocoa powder and extract did not significantly induced uterus growth, cocoa is still considered having estrogenic activity by lowering the correlation between the body weight and uterus weight in ovariectomized rats.
\end{abstract}

Keywords: cocoa, polyphenols, estrogen, uterus, uterotrophy

\section{INTRODUCTION}

Estrogen is reproduction hormone that has primary role in female fertility besides regulating bone and fat metabolism. The main source of estrogen during reproduction is the ovary. During menopause, women suffers from estrogen deficiency due to gradually decreasing function of the ovaries. Estrogen deficiency in women increase the risk of osteoporosis, obsesity, dyslipidemia and hot flushes (Clegg, 2012).

Estrogen works through an interaction with its receptors. There are two types of estrogen receptors, $\mathrm{a}$ and $\mathrm{b}$ receptors. The receptors can also interact with various ligands, thus estrogen can actually be replaced by other compounds. Plants are the source of some estrogen replacement known as 
phytoestrogen (Barros \& Gustafsson, 2011). Plants containing phytoestrogen have traditionally been used for treatment, especially for menstrual disorders (Boonchird et al., 2010; Zingue et al., 2017). Later, phytoestrogen is used as a substitute for synthetic estrogens in the hormone replacement therapy (Leitman et al., 2010).

Blair et al. (2000) stated that a compound should have a cyclical structure in order to bind with estrogen receptor. Furthermore, Fang et al. (2001) suggested that the cyclical structure should consist of at least one benzene ring with the presence of a hydroxyl group. This kind of structure could be found in polyphenol. Indeed, Sstudies stated that most of the phytoestrogens belong to polyphenol group. As example of polyphenols that are also phytoestrogens are genistein, daidzein, naringenin, and reseveratrol (Cos et al., 2003). Polyphenols are also found in cocoa bean in forms of (+)-catechin, (-)-epicatechin, and tannin. Therefore, cocoa polyphenol compounds are potential substitute for estrogen.

Uterotrophy test aims to evaluate the potential of a compound to substitute estrogen. It involves ovariectomized female rodents of which the ovaries, organ producing estrogen, have been removed. An ovariectomized rat will suffer from estrogen deficiency and as the effect, the size of its uterus will decrease. When estrogen substitute is given to the rat, the uterus weight will increase.

The objective of the study was to evaluate the potency of cocoa as the source of estrogen substitute. An experiment was conducted to test the uterus weight of ovariectomized rats following consumption of cocoa powder and extract Development of uterus weight after being given cocoa powder and cocoa extract was compared with those treated with olive oil as vehicle and estradiol valerate as synthetic estrogen. When the cocoa powder and extract can successfully substitute estrogen, the cocoa is considered having an estrogenic activity thus cocoa bean may be formulated to produce a supplement intended for female suffering from estrogen deficiency.

\section{MATERIALS AND METHODS}

Cocoa powder was made from dried fermented cocoa beans with moisture content of $8 \%$. The beans were roasted and shelled. Nibs were pressed to separate most of the fat. Cocoa extract was prepared from dehydrated fresh cocoa beans that were separated from their fat and later were extracted using technical-grade ethanol. The ethanol fraction was then concentrated and spray-dried to produce powdered cocoa extract.

Method developed by Anesini et al. (2008) was used as reference for analysis of total polyphenol content with some modifications. Fifty $\mathrm{mL}$ of $80 \%$ acetone was added to $250 \mathrm{mg}$ of the cocoa powder or cocoa extract, sonicated for 30 minutes in cool condition and filtered. Seventy $\mathrm{mL}$ of distilled water and $5 \mathrm{~mL}$ of Folin-ciocalteu $0.2 \mathrm{~N}$ reagent were added to one $\mathrm{mL}$ of the filtrate. After two minutes, $15 \mathrm{~mL}$ of saturated $\mathrm{Na} 2 \mathrm{CO} 3$ was added, and the solution was kept in room temperature for two hours. The absorbance of the solution was measured on $765 \mathrm{~nm}$ wavelength. The calibration solution was prepared from standardgrade (+)-catechin in acetone at concentrations ranging from 400 to $-1000 \mathrm{ppm}$.

Female wistar rats were acclimatized for at least a week after arrival. The ovariectomy procedure was performed at seven weeks old to remove both of the ovaries. The surgery was carried out by giving $0.1 \mathrm{~mL}$ of ketamine anesthesia for the rats (body weight was between 60 and $80 \mathrm{~g}$ ). The rats were allowed to recover for two weeks prior to treatment. 
The rats were allocated into five groups of treatments and each consisted of six rats. Four groups contained ovarieectomized rats that were given $1 \mathrm{~g} / \mathrm{kg} \mathrm{BW}$ of cocoa powder, $1 \mathrm{~g} / \mathrm{kg} \mathrm{BW}$ of cocoa extract, $10 \mathrm{~mL} / \mathrm{kg} \mathrm{BW}$ of olive oil (vehicle) as negative control or $1 \mathrm{mg} / \mathrm{kg}$ of estradiol valerate as positive control (Progynova, Bayer, Germany) (Bolle et al., 2007). The cocoa extract, cocoa powder and estradiol valerate were dissolved in olive oil. The fifth group consisted of intact rats, which undergone similar surgical procedure but the ovaries were not removed. This group received $10 \mathrm{~mL} / \mathrm{kg} \mathrm{BW}$ of water. Oral administration of the test compound was given once a day for three consecutive days. During the treatment, the rats had free access to water and were fed soy-free food to avoid phytoestrogens intake from soybeans. The research method involving the rats had obtained approval from the Research Ethics Commission of the Faculty of Veterinary, Airlangga University, Surabaya.

Uterotrophic effect was observed based on change in uterus weight after treatment. Necropsy was conducted 24 hours after the last period rats received test substances. Their uterus was taken and the weight was recorded as the wet weight. A hole was made on the uterus and luminal liquid was absorbed. Furthermore, the uterus was weighed again and the result was recorded as blotted weight (OECD, 2007).

The absorbance value from total polyphenol content analysis was correlated to (+)catechin concentration through linear regression equation so that it developed a curve describing the correlation between absorbance and concentration. Mean, standard deviation and normality of the uterus weight from six replications wereas calculated. The data were transformed into $\log 10$ to achieve normal distribution. Variance analysis was performed by involving the body weight as co-variable. Discrepancy in uterus weight was significantce when the significance coefficient ( $p$ ) was smaller than the level of confidence $(\alpha=0.05)$.

\section{RESULTS AND DISCUSSION}

Evaluation of the absorbance value from 400-1000 ppm of (+)-catechin solution in $765 \mathrm{~nm}$ resulted in the correlation between the absorbance and concentration of $\mathrm{Y}=$ $0.0005 X+0.01805(R 2=0.9576)$ where $\mathrm{Y}$ referred to absorbance, and $\mathrm{X}$ referred to concentration. Based on the equation, the total polyphenols of the cocoa extract was $875.2 \mathrm{ppm}$ and that of the cocoa powder was $369.8 \mathrm{ppm}$.

Estrogen was a growth factor for the epithelial cells in the uterus. Ovariectomy removed the ovaries as the estrogen source so that the rats would suffer from estrogen deficiency and the weight of the uterus decreased drastically. Compounds that were able to substitute estrogen could increase the uterus weight of the rats suffering from estrogen deficiency due to ovariectomy (Varayoud et al., 2008; Zingue et al., 2016). This in-vivo approach was known as uterotrophic test which was a method recommended by the National Institutes of Health, USA for evaluation of estrogen replacement compounds (OECD, 2007).

Uterus weight of ovariectomized rats given olive oil was $42 \%$ lower than that of the intact rats; which confirms the findings from previous studies (Stires et al., 2016; Zhang et al., 2016). The average of uterus weight in the intact group was $75.9 \pm 30.2 \mathrm{mg}$, while in the olive oil group was $32.0 \pm 12.4 \mathrm{mg}$. The ovariectomized rats that wereas given estradiol valerate had higher uterus weight $(164.5 \pm 56.8 \mathrm{mg})$ than any other groups. Even though not significant, the ovariectomized rats that were given cocoa extract 


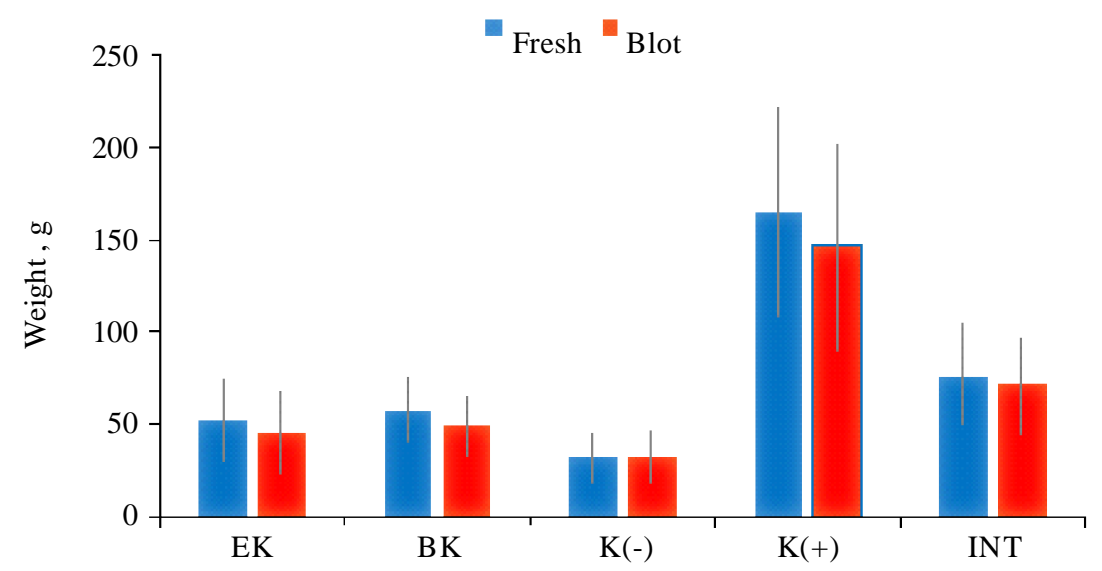

Figure 1. Weight (blue) and blot weight (red) of the mice uterus after the compounds were given for three days. Ovarioectomized mice were given $1 \mathrm{~g} /$ body weight of cocoa powder (BK), 1 g/body weight of cocoa extract, $10 \mathrm{~mL} / \mathrm{kg}$ of $(\mathrm{K}(-))$ olive oil or $1 \mathrm{mg} / \mathrm{kg}$ of $(\mathrm{K}(+))$ estradiol valerat. The nonovariectomized rats were given $10 \mathrm{~mL}$ of water $/ \mathrm{kg}$. (Bar indicated standard deviation of mean)

Table 1. Pearson ooefficient of correlationn (r) between uterus and body weight

\begin{tabular}{lcc}
\hline Treatment & Log10 fresh weight & Log10 blot weight \\
\hline Cocoa powder & -0.058 & -0.062 \\
Cocoa extract & 0.439 & 0.483 \\
Positive control & 0.137 & 0.310 \\
Negative control & 0.927 & 0.939 \\
Non-ovariectomy/intact & 0.480 & 0.482 \\
\hline
\end{tabular}

and cocoa powder tended to have higher uterus weight compared to the ones given the olive oil, i.e. $52.0 \pm 21.7$ and $57.7 \pm$ $18.4 \mathrm{mg}$, respectively.

Covariance analysis showed that body weight had significant influence on uterus weight, both on uterus wet weight and blotted weight ( $\mathrm{p}=0.049$ for $\log 10$ of wet weight, $\mathrm{p}=0.02$ for $\log 10$ of blotted weight). Therefore correlation analysis was performed on the body weight and uterus weight. The correlational coefficient of the olive oil group showed and positive correlation ( $\mathrm{p}=0.927$ ), whereas both of the intact and cocoa extract groups showed moderate correlation; their correlational coefficient was $\mathrm{p}=0.480$ and $\mathrm{p}=0.439$ respectively. There was no significant correlation in the estradiol valerate and cocoa powder groups, in which the correlational coefficients were 0.137 and -0.058 , respectively.
Epithelial cells of the uterus multiplied because of estrogen stimuli, resulted in increased uterus weight which was known as uterotrophy. Related to the two types of estrogen receptors, a receptors played greater role in uterotrophy than $\beta$ receptors. Dupont et al. (2000) reported that estradiol failed to stimulate uterotrophic effect when mice lost $\alpha$-receptor function. In contrast, in the mice that lost $\beta$ receptor the uterus grew rapidly. It is suggested that $\beta$ receptor modulates the uterotrophic effect of the $\alpha$ receptor (Weihua et al., 2000).

Based on this study findings, it was predicted that cocoa extract and cocoa powder were able to replace estrogen in stimulating uterus growth through $\alpha$ receptor. This was indicated from the uterus weight in the cocoa extract and cocoa powder group that were higher than that in the olive oil group. However, the weak uterotrophic effect suggested that cocoa powder and cocoa extracts were 
partial agonists towards the a receptors. Partial agonists referred to compounds that may interact with $\alpha$ receptors but their effects are not equal with the natural estrogens. A study conducted by Weigt et al. (2012) showed that $\alpha$-receptor agonists caused sharp increase in rat uterus weight while $\beta$ receptor agonist did not cause the same result.

Besides estrogen, other proteins such as insulin-like growth factor 1 (IGF-1) and vascular endothelial growth factor (VEGF) may also influence uterus growth (Hastings et al., 2003; Sato et al., 2002). Level of IGF-1 does not depend on body weight but malnutrition led to low IGF-1 level. In contrary, the level of VEGF was closely related to body weight since the level of VEGF spiked in the obese individuals (Loebig et al., 2010).

Strong correlation between uterus weight and the body weight in the olive oil group showed that in the condition of estrogen deficiency, the proliferation of epithelial cells was caused by other factors other than estrogen. It was predicted that when there is lack of estrogen, VEGF takes place in stimulating epithelial cells of the uterus. Decreasing correlational coefficient between the body weight and uterus weight in the cocoa powder and extract group indicates that the VEGF could no longer control the proliferation of the epithelial cells in the uterus. Weihua et al. (2000) stated that the influence of IGF-1 and VEGF on epithelial cells is mediated by the $\alpha$ receptor instead of the $\beta$ receptor. Therefore, it is proposed that the cocoa extract and cocoa powder had inhibited the interaction between VEGF and $\alpha$ receptor.

Correlational coefficient between the body weight and uterus weight in the cocoa powder group was lower than that in the cocoa extract group. It showed that polyphenol level affected uterotrophy. There was indication that polyphenols had greater effect on $\alpha$ receptor at low concentration. Other studies also found that certain compound may exhibit different uterotrophic effect when its concentration varied. Based on a study on genistein, polyphenols in soybean, it was found that differences in concentration affected its uterotrophic activity. As reported by Zin et al. (2013), high dosage of genistein at $100 \mathrm{mg} / \mathrm{kg}$ may stimulate uterotrophy and at the opposite, low concentration of genistein at $10 \mathrm{mg} / \mathrm{kg}$ suppressed the uterotrophy.

\section{CONCLUSION}

Neither $1 \mathrm{~g} / \mathrm{kg}$ BW cocoa extract nor cocoa powder has significant effect towards uterus growth of ovariectomized rats. However, there is possibility that cocoa powder and extract have estrogenic activity. This is concluded from decreasing correlation between the uterus weight and body weight which indicates the interference on $\alpha$ receptor.

\section{REFERENCES}

Anesini, C.; G.E. Ferraro \& R. Filip (2008). Total polyphenol content and antioxidant capacity of commercially available tea (Camellia sinensis) in Argentina. Journal of Agricultural and Food Chemistry, 56, 9225-9229.

Barros, R. \& J.-Å. Gustafsson (2011). Estrogen receptors and the metabolic network. Cell Metabolism, 14, 289-299.

Blair, R.M.; H. Fang; W.S. Branham; B.S. Hass; S.L. Dial; C.L. Moland; W. Tong; L. Shi; R. Perkins \& D.M. Sheehan (2000). The estrogen receptor relative binding affinities of 188 natural and xenochemicals: Structural diversity of ligands. Toxicological Sciences, 54, 138-153.

Bolle, P.; S. Mastrangelo; F. Perrone \& M. Evandri (2007). Estrogen-like effect of a Cimicifuga racemosa extract sub-fraction as assessed by in vivo, ex vivo and in vitro assays. The Journal of Steroid Biochemistry and Molecular Biology, 107, 262-269.

Boonchird, C.; T. Mahapanichkul \& W. Cherdshewasart (2010). Differential binding 
with ER $\alpha$ and ER $\beta$ of the phytoestrogenrich plant Pueraria mirifica. Brazilian Journal of Medical and Biological Research, 43, 195-200.

Clegg, D.J. (2012). Minireview: The year in review of estrogen regulation of metabolism. Molecular Endocrinology, 26, 1957-1960.

Cos, P.; T. De Bruyne; S. Apers; D.V. Berghe; L. Pieters \& A.J. Vlietinck (2003). Phytoestrogens: recent developments. Planta Medica-Natural Products and Medicinal Plant Research, 69, 589-599.

Dupont, S.; A. Krust; A. Gansmuller; A. Dierich; P. Chambon \& M. Mark (2000). Effect of single and compound knockouts of estrogen receptors alpha (ERalpha) and beta (ERbeta) on mouse reproductive phenotypes. Development, 127, 4277-4291.

Fang, H.; W. Tong; L.M. Shi; R. Blair; R. Perkins; W. Branham; B.S. Hass; Q. Xie; S.L. Dial \& C.L. Moland (2001). Structure-activity relationships for a large diverse set of natural, synthetic, and environmental estrogens. Chemical Research in Toxicology, 14, 280-294.

Hastings, J.M.; D.R. Licence; G.J. Burton; D.S. Charnock-Jones \& S.K. Smith (2003). Soluble vascular endothelial growth factor receptor 1 inhibits edema and epithelial proliferation induced by $17 \beta$-estradiol in the mouse uterus. Endocrinology, 144, 326-334.

Leitman, D.C.; S. Paruthiyil; O.I. Vivar; E.F. Saunier; C.B. Herber; I. Cohen; M. Tagliaferri \& T.P. Speed (2010). Regulation of specific target genes and biological responses by estrogen receptor subtype agonists. Current Opinion in Pharmacology, 10, 629-636.

Loebig, M.; J. Klement; A. Schmoller; S. Betz; N. Heuck; U. Schweiger; A. Peters; B. Schultes \& K.M. Oltmanns (2010). Evidence for a relationship between VEGF and BMI independent of insulin sensitivity by glucose clamp procedure in a homogenous group healthy young men. PloS one, 5, 1-5.
Nam, S.; E. Lee; K. Kim; B. Cha; Y. Song; S. Lim; H. Lee \& K. Huh (1997). Effect of obesity on total and free insulin-like growth factor (IGF)-1, and their relationship to IGF-binding protein (BP)-1, IGFBP-2, IGFBP-3, insulin, and growth hormone. International Journal of Obesity \& Related Metabolic Disorders, 21.

OECD (2007). OECD 440 uterotrophic bioassay in rodents. 1-21. A Short-Term Screening Test for Oestrogenic Properties.

Sato, T.; G. Wang; M.P. Hardy; T. Kurita; G.R. Cunha \& P.S. Cooke (2002). Role of systemic and local IGF-I in the effects of estrogen on growth and epithelial proliferation of mouse uterus. Endocrinology, 143, 2673-2679.

Stires, H.; M. Saboya; S.P. Globerman \& W.S. Cohick (2016). Peroral estradiol is sufficient to induce carcinogen-induced mammary tumorigenesis in ovariectomized rats without progesterone. PloS one, 11, 1-17.

Varayoud, J.; L. Monje; T. Bernhardt; M. Muñozde-Toro; E.H. Luque \& J.G. Ramos (2008). Endosulfan modulates estrogendependent genes like a non-uterotrophic dose of $17 \beta$-estradiol. Reproductive Toxicology, 26, 138-145.

Weigt, C.; T. Hertrampf; N. Zoth; K.H. Fritzemeier \& P. Diel (2012). Impact of estradiol, ER subtype specific agonists and genistein on energy homeostasis in a rat model of nutrition induced obesity. Molecular and Cellular Endocrinology, 351, 227-238.

Weihua, Z.; S. Saji; S. Mäkinen; G. Cheng; E.V. Jensen; M. Warner \& J.-Å. Gustafsson (2000). Estrogen receptor (ER) $\beta$, a modulator of ER $\alpha$ in the uterus. Proceedings of the National Academy of Sciences, 97, 5936-5941.

Zhang, J.M.; J. Li; E.W. Liu; H. Wang; G.W. Fan; Y.F. Wang; Y. Zhu; S.W. Ma \& X.M. Gao (2016). Danshen enhanced the estrogenic effects of Qing E formula in ovariectomized rats. Biomed Central Complementary and Alternative Medicine, 16, 181.

$$
* * 0 * *
$$

